of that particular colony, and also proved to be among the three workers of the colony (which consisted of 23 workers and two females) which were most successful at maze-learning.

A virgin female which was originally taken from the same colony but which had been isolated for nearly two months exhibited similar marked jerking movements of antennæ and legs on being placed in a strange plaster nest (she had previously been in a glass one containing earth). These movements soon stopped, however, when another virgin female was placed in the nest with her about one minute later.

I know of no previous records or accounts of similar behaviour in ants.

DFrek Wragge MorLey

Institute of Animal Genetics,

West Mains Road, Edinburgh.

${ }^{1}$ Cook, S. W., Psychosom. Med., 1, 293 (1939).

"Maier, N. R. F., "Studies of Abnormal Behaviour in the Rat" (New York: Harpers, 1939).

\section{Distribution of Lugworms}

ON the muddy sand of the Whitstable flats the casts made by the large population of Arenicola marina L. do not appear to be distributed in random manner at all times of the year. During the summer months there are straight lines, a foot or two wide, along which the casts, and very probably the worms, are more numerous than they are on the adjacent parts of the shore. There is no mistaking these lines, which appear clearly in photographs of the shore. They may be a hundred yards long and are apparently arranged in all directions, being neither all parallel with, nor all at right angles to, high or low tide marks.

We have been unable satisfactorily to account for this grouping; but a few preliminary tests suggest that the layer of soil worked by the worms and which overlies the clay substratum is deeper along the lines than on either side of them. We have not yet been able to discover what is the cause of the difference in soil depth.

We should be very interested to hear if this grouping phenomenon has been noticed on other Arenicola shores and we should be grateful if anyone who has observed it would write to us, especially if he has any explanation to offer.

\section{G. E. NEWELL Garth Chapman \\ Department of Zoology, Queen Mary College, Mile End Road, London, E.1. June 2.}

\section{Life-History of Splachnidium rugosum}

THE peculiar brown alga, Splachnidium rugosum, has been a subject for investigation on a number of occasions. Early workers considered that it should be classed with either the Laminariales or the Fucales. In 1920, Skottsberg' pointed out that the resemblances to those orders were more apparent than real and that its proper position should be near to the Chordariaceæ. Skottsberg went on to suggest that there should be a sexual generation, as he considered the commonly known plant to be asexual, reproducing by zoospores from sporangia borne in the conceptacles.

I have spent some time investigating the lifehistory of this alga, and I can now confirm Skottsberg's suggestions. The sporangia, which are uni- locular, give rise to numerous swarmers which do not fuse and must therefore be zoospores. These swarmers settle down and germinate to give a dwarf, microscopic, branched, filamentous thallus so characteristic of many members of the Ectocarpales and allied orders. This thallus, which is presumably the gametophyte, has been maintained in culture now for more than a year : so far, however, no gametangia have been produced.

The account will be published later in full elsewhere. I wish to express thanks to Prof. V. J. Chapman for his advice during the course of this investigation.

R. J. HOPKINS

Botany Department, University College, Auckland, New Zealand. April 20.

'Skottsberg, C., Svensk. Bot. Tid. (1920).

\section{A Method of Distinguishing between Young and Old Colorado Beetles}

Previous records do not appear to give any indication of how to distinguish between young and old Colorado beetles, except during the first few days following the emergence of the young beetle. I have found evidence that it is possible to separate young and old beetles for a period of at least fourteen days after the emergence of the young adult by means of colour changes in the membranous wings. This fact is of considerable practical importance and assistance to entomologists, especially in countries where the beetle has not yet become an endemic pest.

Trouvelot states (private communication, 1946) that it is only possible to distinguish between young and old beetles for several days after emergence, (1) by the fact that the chitinous integuments remain soft for the first two to three days, after which they become hard like those of the mature beetle, and (2) by the fact that the yellow colour of the elytra takes several days to reach that bright hue so char. acteristic of the mature adult.

In looking for a more satisfactory method whereby young and old beetles could be separated for a longer period of time, $I$ found the colour difference between the membranous wings of the freshly emerged and mature beetles was very marked, and appeared to remain distinguishable, although to a decreasing extent, for approximately fourteen days.

The membranous wings of the fresh emergent are transparent and devoid of colour, while those of the mature beetle are red except for the apex and anal border of the wing. The wings remain colourless for at least four to five days after emergence, and afterwards develop a pink colour which gradually deepens and diffuses over the greater part of the wing surface, especially along either side of the nervures, until the pink colour has given place to a distinct red hue. On an average it takes fourteen to twenty days for the colour intensity to equal that of the mature beetle. This colour change is probably due to the carotene absorbed by the beetle when it commences to feed. Therefore the period taken for the wing to reach the maximum colour intensity will vary within certain limits, according to the temperature and intensity of feeding.

It is hoped to publish fuller details of these findings at some future date.

E. DUNN

States Experimental Station, (States Entomologist) 